\title{
La acogida de la diferencia en la escuela: Condiciones para sumar encuentros pedagógicos
}

\author{
The Acceptance of Difference in School: Conditions to Contribute More Pedagogical Encounters
}

A acolhida da diferença na escola: Condições para adicionar encontros pedagógicos

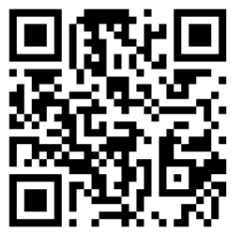

Daniel Gómez-Ramos

Universidad de Barcelona

Barcelona, España

danielgomezramos84@gmail.com

https://orcid.org/0000-0002-4041-1512

\author{
Recibido • Received • Recebido: 20 / 02 / 2019 \\ Corregido • Revised • Revisado: 20 / 09 / 2020 \\ Aceptado • Accepted • Aprovado: 26 / 11 / 2020
}

Resumen: El texto parte de la inquietud por colocar en el centro de la educación el cuidado del otro ser y la responsabilidad ante la vida de la infancia. El propósito del artículo es ofrecer respuestas a la pregunta sobre qué condiciones hacen posible el encuentro entre quienes habitamos la escuela. Desde un enfoque inspirado en la investigación de la experiencia y la fenomenología-hermenéutica, se realizan conversaciones reflexivas con dos maestras y la directora de una escuela ubicada en un contexto de dificultad. A partir de los materiales empíricos registrados junto a las docentes, los textos de investigación realizan una elaboración conceptual que revela algunas claves prácticas para la creación de nuevas dinámicas relacionales que amplían la potencia acogedora de la escuela. Las conclusiones muestran que la desorganización escolar que provoca la diferencia se convierte, a través de un proceso de composición y reinterpretación, en una oportunidad para el encuentro pedagógico.

Palabras claves: Cuidado de la niñez; escuela; gestión escolar; integración escolar; pensamiento ético; práctica pedagógica; responsabilidad educativa.

\begin{abstract}
This paper addresses the concern about the care of the other and the responsibility for children's lives as the core of education. The article aims to offer answers to what conditions make it possible for those who inhabit the school to encounter. Experiential inquiry and phenomenologyhermeneutics are used as methodology. Reflective conversations were held with two teachers and the head teacher at a school located in a tough area. The conceptual elaboration is based on the empirical materials registered with the teachers. It shows some practical keys to create new relational dynamics that expand the welcoming power of the school. The conclusions show that the school disorganization that causes the difference becomes, through a process of composition and reinterpretation, an opportunity for the pedagogical encounter.
\end{abstract}

Keywords: Children's care; school; school management; school integration; ethical thinking; pedagogical practice; educational responsibility. 
http://doi.org/10.15359/ree.25-1.9

http://www.una.ac.cr/educare

educare@una.ac.cr

\begin{abstract}
Resumo: $O$ estudo aborda a preocupação com o cuidado do Outro e a responsabilidade com a vida da infância como centro da educação. $O$ objetivo do artigo é oferecer respostas à questão sobre as condições que possibilitam o encontro entre os que habitam a escola. A partir de um enforque inspirado na investigação da experiência e na fenomenologia-hermenêutica, foram realizadas conversas reflexivas com duas professoras e a diretora de uma escola, localizada em um ambiente difícil. A partir dos materiais empíricos registrados junto com as docentes, os textos de investigação realizam uma elaboração conceitual que mostra algumas perspectivas práticas para a criação de novas dinâmicas relacionais que ampliem o poder acolhedor da escola. As conclusões mostram que a desorganização escolar que provoca a diferença torna-se, por meio de um processo de composição e reinterpretação, uma oportunidade de encontro pedagógico.
\end{abstract}

Palavras-chave: Cuidado da infancia; escola; gestão escolar; integração escolar; pensamento ético; prática pedagógica, responsabilidade educacional.

\title{
Introducción
}

Este trabajo es fruto de un proyecto de investigación ${ }^{1}$ que tiene el propósito de estudiar los saberes profesionales de docentes que, al establecer relaciones de cuidado con su alumnado, hacen posible que este prospere en su aprendizaje y crecimiento personal. El interés global es profundizar en la comprensión sobre la responsabilidad y el cuidado de niños, niñas y jóvenes en el oficio de educar (Brailovsky, 2019; Clandinin et al., 2016; Kohan, 2019). Los resultados dan cuenta del sentido ético que sustenta y guía esta actitud pedagógica y cómo influye en las relaciones educativas que mantenemos con la niñez y la juventud. Otra contribución de este trabajo es la concreción de algunas de las disposiciones y de los gestos mediante los que se manifiesta el "cuidado responsable del otro sujeto" en la práctica cotidiana.

Las aspiraciones mencionadas han motivado un estudio del cuidado-responsabilidad como un saber producido en una relación de pensamiento con la experiencia vivida, un modo de saber existencial y holístico que se elabora por medio de un pensar creativo con lo que se vive (Ayala Carabajo, 2018; Contreras Domingo, 2016). Es un saber emergente, porque dispone a interrogarse por lo adecuado ante una situación singular; pero también es sedimentado, en tanto proporciona un bagaje reflexionado y una orientación para la acción (Ávalos et al., 2019; Contreras Domingo, 2017).

Con el objetivo de percibir las cualidades del fenómeno estudiado con mayor claridad y amplitud de matices, la indagación se desarrolló en una escuela ubicada en un contexto empobrecido de la periferia de Barcelona a la que asistía una niñez en particulares circunstancias de vulneración, con tres maestras de extensa trayectoria profesional y especialmente

${ }^{1}$ Relaciones educativas y creación del currículum: Entre la experiencia escolar y la formación inicial del profesorado. Indagaciones narrativas (EDU2016-77576-P), I+D+i financiado por el Ministerio de Ciencia, Innovación y Universidades para el período 2017-2019, dirigido por el Dr. José Contreras Domingo, de la Universidad de Barcelona.

2 
http://doi.org/10.15359/ree.25-1.9

preocupadas por el cuidado de la infancia y la responsabilidad pedagógica. Para ello se mantuvieron conversaciones hermenéuticas (Sierra Nieto y Blanco García, 2017) con las docentes profundizando a lo largo de un curso escolar en las inquietudes de este estudio y ampliándolas. Las tres docentes fueron las impulsadoras y creadoras del proyecto educativo del centro: María², profesora de educación infantil; Diana, profesora de educación primaria; y Claudia, profesora en primaria y directora de la escuela.

La intención de las conversaciones hermenéuticas no fue ahondar en los saberes propios de las maestras ni identificar y documentar las buenas prácticas de su proceder, sino recibir sus formas de hacer y de pensar como situaciones experienciales (Sierra Nieto, 2019). Es decir, como acontecimientos novedosos que requerían ser pensados por el investigador para producir los sentidos y los significados que revelarían las diversas dimensiones pedagógicas que la responsabilidad y el cuidado verifican en el mundo empírico.

\section{Marco teórico ${ }^{3}$}

El encuentro con la llamada de la vulnerabilidad de la niñez es un acontecimiento ético, puesto que su singularidad solicita la ayuda mediante una respuesta concreta y situacional: reconocerla, acogerla sin condiciones y ofrecerse a acompañarla (Bárcena y Mèlich, 2014). La relación pedagógica hunde sus raíces en la responsabilidad ética, en la radical dependencia del otro ser de nuestra escucha, atención y cuidado, y de que nuestra respuesta debe hacerlo progresivamente responsable de sí y del otro sujeto. Según Lévinas (2015), el lazo social se anuda en la preocupación y ocupación por el prójimo, pues lo que da sentido al Yo es cuidar de la otra persona; de hecho, la responsabilidad es la estructura esencial, primera y fundamental de la subjetividad.

¿Qué implicaciones pedagógicas tiene esta disposición subjetiva? ¿Mediante qué gestos se materializa en la relación educativa? ¿Cómo opera el lenguaje ético del cuidado responsable? ¿Qué efectos tiene en la subjetividad de la niñez?

Tomar conciencia de lo extraordinario de la llegada de un niño, una niña o joven implica dejarse conmover por la vulnerabilidad de su condición, lo cual demanda al educador volverse sensible, vulnerable y receptivo a la experiencia afectiva y emocional que abre al yo al encuentro con la alteridad. Dice Lévinas (2015) que la responsabilidad pedagógica brota en una

\footnotetext{
2 Para preservar la intimidad y cuidar a las docentes y a la niñez con la que trabajan, se ha decido usar nombres suplantados para identificarlas; del mismo modo que tampoco se hace mención a espacios ni lugares concretos para que el centro educativo donde trabajan no pueda ser reconocido.

${ }^{3}$ Este epígrafe solo pretende esbozar un primer enfoque conceptual, puesto que las referencias teóricas se van desarrollando a lo largo de todo el cuerpo del artículo con el objetivo de sostener la actividad indagadora.
} 
http://doi.org/10.15359/ree.25-1.9

http://www.una.ac.cr/educare

educare@una.ac.cr

persona cuando percibe las necesidades de un niño, una niña o joven y se siente reclamada a responderlas haciéndose cargo de su vulnerabilidad. Solo entonces, siendo sensible a la fuerza de su fragilidad, sintiendo su voz como una interpelación y experimentando a través de la responsabilidad la autoridad que el niño, niña o joven concede, el sujeto adulto está en posición de hacer algo cuidadoso por esta persona.

Partiendo de los relatos y las comprensiones que tres docentes comparten acerca de una experiencia escolar, este artículo analiza cómo una escuela puede alojar y crear encuentros entre diferentes modos de vida.

En tanto un cuerpo se resiste a ser reconocido por la imagen de estudiante o de niño o niña que se tiene modelada en la conciencia, su existencia inquieta el orden establecido de la escuela y coacciona a los grupos educadores a replantear una forma organizativa capaz de acoger su llegada (Garcés, 2016). En vez de centrarse en el déficit y en lo ausente que borran lo singular de todo otro ser, con la intención de restituir el esquema perdido, la cuestión es percibir qué elementos, situaciones y cuerpos se muestran, se desplazan, y actuar transformando la estructura.

Uncuerpo excedecualquier ontologíay todo diagnóstico, uncuerpotiene unas capacidades de afectar y de ser afectado y se orienta en el mundo en relación con esas afecciones (Deleuze, 2006). En el momento en que una estructura se ve caotizada por un cuerpo: problematizar la situación significaría explorarla y llevarla hacia lo desconocido. No tratar de introducir al otro en un esquema predefinido con el objetivo de reponer el orden instituido lo antes posible, sino inventar nuevas distribuciones entre los cuerpos y los conceptos (Deleuze y Guattari, 2010).

Problematizar significa intervenir en lo que sucede para abrirlo y generar modificaciones en el formato único cuyos efectos sean múltiples e insospechados. La práctica pasa por afirmar aquello que trae perturbación y desorientación a la estructura dada, en lugar de negarlo o de intentar hallar el modo de detenerlo. Se trata de ensayar y tantear en medio de experimentaciones inusitadas, no adaptarse a los preceptos decretados por un modelo de escuela.

Es preciso fugarse de la impostura atribuida y de la perspectiva institucionalizada para emprender la capacidad de interrogarse: ¿cómo acompañar a un cuerpo que posee una potencia que excede las certidumbres pedagógicas? Es preciso aceptar el desacomode de las presunciones escolares y arriesgarse a derivar del rumbo normal de la planificación para conseguir leer los recursos, la lucidez, las argucias, las destrezas y el saber que permiten a un niño o una niña relacionarse con el mundo de una forma singular. Una forma que se convierte en pregunta: ¿cómo acoger y componer un encuentro con su presencia?, ¿cómo establecer una relación educativa entre modos de vida diferentes?

Para abordar estas inquietudes, el estudio enmarca sus principales conceptos basales en el corpus teórico desarrollado por el pensamiento posestructural y las prácticas afirmativas de 
http://doi.org/10.15359/ree.25-1.9

los filósofos Deleuze y Guattari (2013), nutriéndose también del método de la intuición y la visión creadora de los escritos de Bergson (2016). Por otra parte, la investigación toma como inspiración las ideas de vulnerabilidad y responsabilidad desplegadas en la ética de la alteridad del fenomenólogo Lévinas (2015).

\section{Metodología}

Dada la complejidad epistémica del saber pedagógico, esto es, que no se deja reducir a técnicas cerradas y procedimientos acabados, pues su carácter es holístico, integrado, relacional, emocional, corporal, valorativo y ético, se decidió configurar una metodología inspirada en la investigación de la experiencia educativa y en la fenomenología-hermenéutica (Clandinin et al., 2018; Contreras Domingo y Pérez de Lara Ferré, 2010; Dewey, 1998; Gadamer, 1977; van Manen, 2003), con el objetivo de pensar con la experiencia y producir sentido. Esta disposición subjetiva de indagación supone habitar la escuela como sujeto de exposición y recepción de la alteridad de los otros seres, del mundo y de la propia de cada quien, implica atender y captar el fenómeno como algo que, al acontecer, provoca en la sensibilidad una inquietud educativa. Un afecto que da forma a un signo o hilo de sentido que solicita de la conciencia una significación mediante el pensamiento (Arbiol González, 2018).

Si algo resuena subjetivamente es porque la conversación funciona como una experiencia vivida que despierta una pregunta o conecta con una necesidad, signos que hablan de una búsqueda de sentido pedagógico. El hilo de sentido es experimentado por la reflexividad como el acontecer de una exterioridad que nos deja pensando o que nos da qué pensar. Desde diversas orientaciones (Biesta, 2017; Najmanovich, 2019; Skliar, 2017) se entiende el acontecimiento como un encuentro entre la experiencia y el pensamiento que tiene el poder de extrañarnos de lo conocido, desplazarnos del propio punto de vista, incomodar nuestros presupuestos y hacernos dudar de nuestras palabras. Lo que acontece en la experiencia de conversación con las docentes contiene la posibilidad de producir una nueva elaboración de los significados de nuestras acciones y actitudes.

Los momentos metodológicos pueden enumerarse con la siguiente secuencia: (1) percepción del fenómeno en conversación, (2) escritura en el diario de campo o grabación y transcripción de la conversación, (3) dilucidación de interrogantes e hilos de sentido, (4) construcción de fragmentos de conversación -textos de campo-, (5) amplia consulta de corpus teórico y (6) comprensión a través del ensayo como modo de interpretación y reflexión -textos de investigación-. Durante el proceso se llevó a cabo una triangulación ambiental (Meneses et al., 2019): al regresar cada día a la escuela y a la conversación con las docentes, lo escuchado y analizado volvía a contrastarse y dilucidarse dando origen también a una nueva revisión y alimentación teórica para, finalmente, desembocar en el tratamiento investigativo como una 
http://doi.org/10.15359/ree.25-1.9

http://www.una.ac.cr/educare

educare@una.ac.cr

comprensión más profunda y contextualizada del tema estudiado. De esta manera, la escritura resultante del estudio se torna un producto confiable en cuanto permite al lector o lectora reconocer en el texto sus inquietudes y hacerse sus propias preguntas.

Después de la percepción del fenómeno en la conversación, en mi diario de campo tomaba notas descriptivas de las palabras que compartía con las docentes, y de lo vivido y de lo pensado junto a ellas en la escuela. A partir de esas anotaciones y de las transcripciones de las grabaciones, relataba varios fragmentos de conversación (FC): textos de campo que no lo dijeran todo de la experiencia, que no clausuraran su potencia significativa, pero cuya lectura tuviera la capacidad de suscitar los interrogantes que se me habían desvelado.

Un fragmento de conversación muestra un material sensible con el que seguir elaborando un pensar con la experiencia con el que trazar diversos caminos de escritura mediante los que ir ahondando reflexivamente en las dimensiones pedagógicas que había implicadas en el fenómeno registrado. El diálogo entre los textos del material experiencial-sensible y la documentación de literatura teórica fue descubriéndome temáticas de investigación, enfocando con precisión mis preguntas y captando los hilos de sentido susceptibles de ser explorados.

Para los textos investigativos se empleó la escritura ensayística (Adorno, 2003) que permitió sostener un trabajo de ampliación y profundización en el abordaje de las cuestiones educativas que residían en los textos compuestos durante la estancia en la escuela y los encuentros con las docentes. Porque el ensayo procede indagando experimentalmente con el tema de estudio desde diversas vertientes y lo hace estableciendo con lo vivido una distancia poética: creando, revelando o trayendo al presente algo valioso. El lenguaje del ensayo es un lenguaje con alguien dentro, un lenguaje frágil y heterogéneo, cuyas palabras se quieren evocativas, pero siempre preocupadas por la pluralidad y la transferencia de conocimiento de la investigación educativa.

\section{Resultados y discusión}

Como resultado se presentan cuatro hilos de sentido tejidos en una trama de categorías cuya elaboración fue realizada a partir de la articulación entre: (1) los propósitos de la investigación, (2) la experiencia vivida en las conversaciones, (3) la identificación de diferentes signos de los acontecimientos y (4) la elaboración conceptual (Deleuze y Guattari, 2013) mediante un pensamiento entendido como producción de nuevos efectos de sentido que tratan de hacer justicia a la multiplicidad semántica de lo real (Larrosa, 2017). Dado que el estudio es más amplio, a continuación, se muestran algunos de los asuntos más relevantes sobre los que se ha decidido indagar con mayor exhaustividad. 
http://doi.org/10.15359/ree.25-1.9

Darse un cuerpo vulnerable (no erudito)

En esta clase (P5), Lucio no consigue sostenerse. Hoy ha entrado al aula a las 9:00 y a las 9:10 ya no podía aguantar más y se ha desahogado con el compañero de al lado. Sólo habían pasado 10 minutos de su llegada y ya tuve que pedirle que se sentara en otro lugar. No es sólo Lucio, también Erik, Valeria y Héctor que tratan mal a sus compañeros cuando no te lo esperas. No puedo garantizar la protección y el cuidado de todos los niños del grupo. Se vive un fuerte nerviosismo porque a los niños les puede caer un golpe en cualquier momento.

Era imposible continuar de esta manera, no podíamos seguir sosteniendo esta situación. El grupo de P5 es incapaz de satisfacer las necesidades de Lucio, por eso hemos creado un plan para él. Permanece la mitad de la mañana, en ocasiones toda la mañana, en el aula de $3^{\circ}$ de Primaria. Con el grupo de $3^{\circ}$ está más tranquilo, ocupa otro lugar muy distinto que en P5. Está despierto hacia el mundo, tiene interés por aprender, parece que le da sentido estar en el grupo de mayores. (MaRíA_FC_07)

Pensar significa pensar lo que aún no ha sido pensado, de ahí que no sea posible pensar sin devenir otro (Deleuze, 1987). Pensar una institución como la escolar quiere decir multiplicar las posibilidades de vida que ofrece. Lo que implica escapar de las identidades fijas y salirse de los papeles ya instituidos para experimentar la diferencia. En la escuela, exponerse a la experiencia de la diferencia equivale a diluir los modos de ser que aparecen preestablecidos. La diferencia es el acontecer de un afuera que provoca un extrañamiento en la forma homogénea y la coacciona a probar, si es posible fugar a otra forma.

Diferencia no significa agrupar identidades o tolerar la diversidad, la diferencia es un proceso activo a través del cual intentar creaciones que convengan (Deleuze, 2002). Tal como muestran los fragmentos de conversación, la diferencia se expresa cuando las maestras renuncian a los límites estrictos de su rol institucional con el propósito de pensarse más allá de los puntos de vista y de los conocimientos docentes. La diferencia se expresa cuando una escuela se fuga de la rigidez de su esquema para seguir trabajando como escuela. Diferencia es moverse hacia fuera de los lugares definidos para aumentar las potencias de encuentro y de relación con Lucio. A partir de la situación que Lucio inaugura en la escuela, ¿qué preguntas inquietantes pueden ser formuladas para huir de los presupuestos y provocar devenires impensados? Las maestras abandonan la función maestra -aquella que dice poseer el saber, los razonamientos y la única verdad-para hacerse vulnerables a las afectaciones propias de experimentar la diferencia.

Lucio representa un afuera que violenta el pensamiento de las maestras, un acontecimiento impensado que invade la percepción y la conciencia (Deleuze, 2002). La existencia del niño altera la sensibilidad pedagógica, algo hace ver y sentir de otro modo, lo cual fuerza la activación del pensamiento. Se piensa porque se necesita, es decir, porque una situación se ha convertido en 
http://doi.org/10.15359/ree.25-1.9

http://www.una.ac.cr/educare

educare@una.ac.cr

insostenible. No se piensa por voluntad o porque se quiere modificar una realidad, se piensa porque algo produce inquietud. El pensamiento no está empujado por el cumplimiento de un propósito, está coaccionado por la apremiante necesidad de derivar una nueva manera de vivir con otras personas. No se piensa para realizar una imagen previa de Lucio (debería de ser cívico, disciplinado y obediente), se piensa porque Lucio obliga al pensamiento a crear una forma escolar que está por conocerse.

Porque la vida es un flujo constante de movimientos, pensar es tratar de registrar las transformaciones, estudiar sus efectos e indagar cómo las inconsistencias hallan su manera singular de consistir (Deleuze y Guattari, 2013). En el momento en que alguien con la potencia de Lucio entra en intercambio con la estructura escolar, la propensión es tematizar al niño mediante una categoría para reconocer en él aquello que obstaculiza los objetivos previamente instituidos. Diagnosticar al sujeto como problema ayuda a decidir qué resolución aplicar para reponer, con urgencia, la consistencia de la estructura que dicho sujeto ha puesto en riesgo. Se trata de proceder explicando la realidad desde un marco de inteligibilidad para controlarla y apropiarse lo que en ella sucede. La creencia de que se puede describir acabadamente al otro ser o la realidad apacigua la inquietud que provoca la incertidumbre, así como la creencia de que se conoce con seguridad la acción correcta. La opción elegida, generalmente, es coleccionar un compendio de soluciones, prevenciones y recetas (terapia individual, derivación a otros centros, adaptaciones curriculares, actividades especiales, agrupaciones específicas, etc.). Pero lo real siempre escapa a las redes conceptuales, el otro ser excede cualquier tematización, por ello buscamos hacer que desaparezca (modificarlo, apartarlo o abandonarlo). No obstante, la inquietud provocada por una pasión del afuera (Deleuze, 1987) es connatural al auténtico pensamiento y conlleva una labor investigativa que pone en crisis lo normalizado.

Sin embargo, las inconsistencias que acontecen en la escuela pueden percibirse como un desafío para el pensamiento pedagógico: ¿cómo componer en la escuela una estructura al servicio, no de la reproducción, sino de lo común? No es la reproducción de esquemas y estados invariables lo que convoca las preguntas por las condiciones del encuentro educativo, sino las inconsistencias: ¿qué organización configurar para que cualquier existencia pueda crecer en esta escuela?

\section{Desorganizarse, moverse con lo moviente}

Desde el inicio de curso y todos los días, de pronto Lucio se escapaba del aula de P5 y echaba a correr por la escuela. En lugar de perseguirlo y castigarlo, decidimos observar qué hacía y a dónde acudía. ¿En qué dirección apunta su deseo? ¿Deja de huir cuando encuentra qué? ¿Cómo configurar una organización que le sea interesante? Al principio se escapaba al patio y se quedaba deambulando él solo. Hasta que se aburrió y comenzó a recorrer otros espacios. 
http://doi.org/10.15359/ree.25-1.9

Así un día halló el aula de $3^{\circ}$ de Primaria y empezó a visitarla todos los días en sus fugas. (CLAudia_FC_27)

El método de la intuición (Bergson, 2016) trata de percibir la naturaleza de un cuerpo que radica, no en una esencia invariable o en la graduación en que responde a ella, sino en su permanente movimiento y en los variados efectos que provoca. Si al observar a un niño agitado agrediendo a otros niños o a una maestra, se aplican unos conocimientos para desarrollar competencias para ser menos agresivo, más respetuoso o comportarse normal: se están percibiendo estados fijos, pero se desatiende lo moviente.

La intuición percibe las más pequeñas transformaciones en el moverse de los cuerpos y las cosas entre las diferentes polaridades. ¿Qué hizo posible que un cuerpo o una situación se alteraran? ¿Qué variar para hacer que un cuerpo o una situación se muevan? Percibir el movimiento requiere ponernos en movimiento. Según Bergson (2016), la definición de lo posible como la realización de un ideal o de un valor precedente constituye un falso problema. Lo posible está virtualmente en el movimiento y, para ser actualizado, requiere que se perciban los cuerpos y las situaciones fugándose de sus estados fijos.

Lo virtual es la experiencia de lo intolerable que supone la situación con Lucio, es decir, algo exterior a las certezas escolares produce un acontecimiento que sacude y cuestiona la forma en que se pensaba hasta el momento. En este sentido, un virtual sería"no se puede tolerar más esta situación" y su actualización consistiría en poner en marcha recursos para imaginar composiciones posibles entre Lucio, la escuela y las maestras. Otros virtuales son: la voluntad del niño de perseverar en su ser (por fuera de las imágenes de quién debería ser), el poder que tiene para esforzarse e incrementar sus capacidades (más allá de los prejuicios de correcto o incorrecto), su fuerza para relacionarse y desarrollarse con otros cuerpos (sorteando los ideales de lo bueno y lo malo), la destreza de su existencia para desordenar la estructura e instalar la llegada de la multiplicidad (lo que pide abandonar el narcisismo docente).

Las maestras han inaugurado un campo de experimentación donde ensayar e intentar qué posibilidades van cogiendo cualidades consistentes. Prueban a inventar nuevos movimientos en las relaciones entre los cuerpos y nuevas modificaciones en los espacios y en los tiempos de la organización para leer qué efectos van manifestándose. Los virtuales se actualizan en el momento en que las maestras registran, en la potencia de Lucio, un movimiento y no una manera artificiosa de clasificarlo. Las maestras advierten en el niño una subjetividad en movimiento que no deja de buscar cómo, con quién y con qué realizar intercambios para afirmarse en su ser, para amplificar sus potencias (Deleuze, 2006). En vez de interpretar cuál es la interferencia que impide la consumación de un objetivo a partir de un hecho y así precisar cuál es la fórmula adecuada para su resolución, las maestras se preguntan por los significados de los signos que emite Lucio, por las capacidades que pone en juego el niño y por qué podrían sumar a su forma de existir que consiguiera despertar su deseo por la escuela. 
http://doi.org/10.15359/ree.25-1.9

http://www.una.ac.cr/educare

educare@una.ac.cr

Lucio conlleva una experiencia de diferenciación que suspende las leyes trascendentes de la institución educativa, las maestras no hacen de sus decisiones normas morales, sus acciones son tanteos que indagan éticamente. La cuestión pedagógica es explorar qué respuesta funcionaría en un momento particular, en una distribución de cuerpos y objetos circunstancial. La respuesta que funciona no es la que reproduce un orden de cosas prescrito, sino la que desvela un territorio interesante para continuar ensayando. Si el descubrimiento de este territorio no se produce, las maestras se encaminan a probar otras posibles respuestas. Cuando un problema se plantea partiendo de la semejanza con una realidad antecedente es un falso problema (Bergson, 2016): porque la situación es siempre extraordinaria e inimitable, le atañe una respuesta otra.

La intrusión de Lucio funciona como un afuera que problematiza la organización de la escuela impulsando a las maestras a un pensamiento que sale del interior de los fundamentos escolares para trabajar en un estado de exterioridad (Deleuze, 1987). Intromisión de una heterogeneidad en una homogeneidad que provoca un desorden que exige la invención de una nueva y diferente ordenación. La consecuencia del signo (o afuera no-pensado) es experimentar la impotencia natural del pensamiento $\mathrm{y}$, de este modo, violentarlo para que active su mayor potencia (Deleuze, 2002).

Problematizar es plantear un interrogante que tenga el poder de provocar un movimiento en los cuerpos implicados y en la situación. Es asumir los afectos causados por el acontecer de la diferencia para pensar aquello que no se ha sabido pensar aún. Para Bergson (2016), intuir no corresponde a comparar y armonizar sujetos u objetos en el interior de los criterios orden y desorden, ser y no-ser o más y menos, porque en esas dimensiones no ha lugar a la exterioridad radical de la diferencia. La intuición no pasa por comprobar o refutar si lo que hace una docente es adecuado o inadecuado, o si lo que hace un estudiante está bien o mal, según unos guiones diseñados de antemano. Intuir es revelar las posibilidades que se mueven casi imperceptibles y sumar a la realidad alguna condición hasta ahora ignorada.

Lucio desafía a las maestras en su capacidad de intervenir en lo común y en su sensibilidad para ser afectadas por la pregunta por lo común (Deleuze, 2006). El niño las convoca a pensar cómo configurar un mundo nuevo en la escuela, no en función de un ideal abstracto de lo que debería ser una institución educativa, sino un mundo fundado partiendo de la disponibilidad de los cuerpos, las cosas y las situaciones existentes. ¿Cómo establecer una relación con el territorio de Lucio para que el niño encuentre la manera de componerse con el territorio de la escuela? ¿Qué objeto cultural atractivo y desafiante se coloca entre Lucio y las maestras para que tenga lugar una experiencia educativa? ¿Qué actividad o proyecto tendría la cualidad de invitar al deseo de Lucio a querer quedarse en la escuela? 
http://doi.org/10.15359/ree.25-1.9

Las maestras trabajan intuitivamente en tanto sortean el formato único escolar para pensar lo que ocurre con Lucio desde la curiosidad y la experimentación (Deleuze, 1987). Se posicionan subjetivamente desde la conciencia de su propia vulnerabilidad para emplear su pensamiento como un recurso de invención, y no tanto como una competencia a las órdenes de una ley organizadora. La intuición deja de lado los clichés que reducen la realidad a explicaciones indiscutibles y construyen falsos problemas que llevan a respuestas debilitantes.

\section{Pensar fugando hacia otra distribución}

En clase de $3^{\circ}$ de Primaria, Lucio participa y comparte con niños que le sacan 3 o 4 años. Hace lo mismo que hacen los demás, conecta con ellos y con lo que pasa en el aula. Cuando leemos o escribimos y él me dice "es que yo no sé", yo le explico que esto es lo que hacemos aquí y que puede volver a P5 si quiere. Pero Lucio escucha el chaparrón y no se rebota ni me dice "idéjame!". Al contrario, lo vive como un desafío, porque para él es un reto estar con los mayores y se esfuerza por seguir las tareas que ellos realizan.

Es interesante ver cómo un niño de P5 sostiene el tipo ante una situación que lo coloca en una fuerte inestabilidad. No se intimida, no se asusta. Su deseo es hacer lo mismo que los mayores, aunque, en principio, desconoce la forma. Como Lucio no sabe leer, copia lo que aparece en la página, lo escribe sin saber escribir. Simula o aparenta que hace las cosas que hacen los mayores, hace como que lee y hace como que escribe. Y en esa imitación de los grandes, Lucio acaba leyendo y escribiendo.

"Hacer como si" es una potencia que Lucio tiene y de ella estamos estirando para ver qué sucede. También tiene la capacidad de resistir ante la frustración, es perseverante y cuando quiere aprender algo lo intenta y practica. Si lo hace mal, lo aguanta y no se cansa fácilmente. (DIANA_FC_26)

Las huidas de Lucio pueden interpretarse como un abandono de lo escolar y de las tareas de estudio o pueden interpretarse como una manera que el niño tiene de destapar otro mundo, de ingresar en otro modo de vida. La escapada entendida como el trazado de una línea de fuga que perfora y traspasa el destino prescrito. La fuga percibida como la apertura de un territorio habitable, a partir de una estructura inhabitable (Deleuze y Parnet, 1980). Fugar es la expresión de un cuerpo agotado: escapar de una forma de existir que disminuye su potencia para dirigirse hacia una forma de existencia distinta. La huida de Lucio comunica a las maestras la búsqueda del niño para salir del malestar, el intento para eludir las pasiones tristes que siente en determinadas dinámicas escolares. El deseo de Lucio, para lograr perseverar en su ser, lo impulsa a inventar otros modos de consistir y encontrarse con los demás. Huir es una herramienta que el niño tiene en su haber para sobrevivir, eludiendo aquellas vinculaciones que descomponen su deseo induciéndole debilidad. 
http://doi.org/10.15359/ree.25-1.9

http://www.una.ac.cr/educare

educare@una.ac.cr

María, Claudia y Diana leen las huidas de Lucio como signos para preguntarse cómo la escuela sería capaz de huir con el niño. Huir del formato escolar, no para renunciar a la responsabilidad pedagógica sino precisamente para afirmarse en ella e incrementar el poder de acogida de la institución. Las maestras interpretan las fugas de Lucio como oportunidades para transitar a través de una experiencia de la diferencia que les permita imaginar la construcción de un mundo escolar capaz de alojar y sostener a Lucio. El personal docente de la unidad educativa está cansado, frustrado, debido al fracaso de la repetición de las medidas y respuestas habituales, prefiguradas. Lo que hace Lucio es invitar a las docentes y los docentes a organizar otra estructura y a repensar nuevos modos de intercambio. La presencia de Lucio resulta desafiante en tanto abre la pregunta acerca de qué habilidades y conocimientos porta la niñez y cómo la escuela puede componer un encuentro con ello. En el momento en que una situación se torna intolerable surge un desasosiego, pero, a la vez, surge la posibilidad de una modificación en la distribución de deseos. Acontece una brecha en las certidumbres y convicciones, una inseguridad a través de la cual puede emerger el deseo de configurar una trama común probando encuentros insospechados e intercambios insólitos. Se trata de trasformar el bloqueo que causa cansancio en un problema afirmativo, en un interrogante que solicita pensamiento para crear una vía por la que fugarse e inaugurar nuevos territorios.

No es lo mismo decir niño problemático, con lo cual estamos diciendo que Lucio es un obstáculo para conseguir nuestros objetivos, a decir que el niño problematiza las metodologías y la organización instituida (Garcés, 2016). Este último enunciado representa una afirmación que ofrece la posibilidad de una consistencia a ensayar. Lucio supone una negatividad para la escuela, porque no puede dejar de desterritorializarse de la posición que le asigna la institución. Cuando se fuga lo que hace es destapar otros territorios donde componerse de forma positiva y así poder aumentar su potencia. Las maestras acompañan la línea de fuga que lidera el niño para experimentar intercambios que las aproximen a un encuentro entre él y lo escolar. Lo que parece una simple colisión entre cuerpos es captado por las docentes como la ocasión de establecer relaciones. Si Lucio no puede a adaptarse a los lugares, tiempos y modalidades de la escuela, ¿cómo imaginar una escuela en la que Lucio sí pueda? Lo que empuja al pensamiento a acoger la diferencia con la que el niño llega a la escuela, para que esta pueda reterritorializarse junto a la singularidad de Lucio: qué escenarios, qué temporalidades, qué vinculaciones, en qué grupos, qué objetos culturales, qué actividades, etc. materializar en la escuela para lograr albergar su existencia.

Problematizar es leer las inconsistencias como signos que desacomodan las significaciones establecidas y coaccionan a los sujetos a pensar; signos que señalan la colisión con algo o alguien que se resiste a ser aprisionado por una representación. Lucio no consiste con la denominación sujeto educativo: que aprende regularmente, que reconoce la autoridad de las personas adultas, que repite comportamientos normalizados, que tiene una cierta disciplina, etc. "El niño no atiende" o "El niño no entiende" reproducen falsos problemas que ignoran la 
http://doi.org/10.15359/ree.25-1.9

heterogeneidad de las formas de existencia, $y$, por este motivo, funcionan como ejercicios de dominación. “¿Qué hacer para que Lucio se incluya o no se escape?" es un interrogante que interpreta la inconsistencia como una interferencia entre la realidad y las propias expectativas, es decir, como algo que falta y debe ser completado: la resolución al problema es que el niño ha de cambiar para llegar a satisfacer determinados propósitos. Formular un verdadero problema no es implementar una solución que preexiste a la situación, al contrario, tiene que ver con ampliar los diferentes modos de expresividad, con configurar asociaciones entre múltiples potencias y con construir una conjetura que demanda verificaciones (Deleuze, 1996). En tanto Lucio es un signo que se fuga de las significaciones acostumbradas, el verdadero problema consistiría en zambullirse en una producción activa para tratar de agregar y extender las ocasiones de intercambio entre el niño y el mundo. Las docentes parecen interrogarse: ¿cómo componerse con los niños y niñas que escapan de un sistema codificado? ¿cómo nos afecta un niño o niña que decida huir en lugar de permanecer en la escuela? ¿qué actividad u objeto poner entre el niño y la niña y la escuela que permita seguir caminando de manera conjunta?

En lugar de centrarse en las causas privadas que -aparentemente- explicarían las razones de por qué Lucio se fuga, las docentes centran su atención en desentrañar cuáles son las posibilidades que hay en la situación para producir sentidos pedagógicos (Deleuze y Parnet, 1980). Las escapadas de Lucio informan a las maestras de la incapacidad de la escuela para repensarse como escuela y de la propia dificultad de sí mismas para repensarse en tanto educadoras. Pero no se inmovilizan en una queja lastimera, no se ocultan tras estereotipos y leyes estructurantes. Asumen la descolocación de sus posiciones habituales e inician una conversación con los signos para experimentar con opciones de colaboración inauditas (Deleuze, 1996). Lejos de señalar con el dedo al entorno familiar como origen de la -supuestaconducta inadaptada de Lucio o actuar tematizando al niño, opciones que lo fijarían en su rol de niño problema, las maestras aceptan la inquietud y recorren el itinerario de diferenciación que Lucio les propone como un problema propio. Se trata de extraerse de la lógica binaria que confronta el orden simbólico del niño con el orden simbólico de la escuela, para empezar a investigar el reto de escribir un relato en común.

\section{Generar alianzas desde la sensibilidad}

Sin embargo, en P5 lo habitual es no soportar ninguna desavenencia y enojarse rápidamente. Su deseo se despierta en $3^{\circ}$ y con él sus potencias. Cuando viene a clase con los de $6^{\circ}$ de Primaria también está más tranquilo y se muestra más dispuesto a aprender. Se esfuerza por ir más allá de lo que puede. De hecho, en $6^{\circ}$ puede más que en P5. Es como si fuera otra persona diferente. Por ejemplo, los miércoles viene al huerto con los mayores y él cava y riega como los de $6^{\circ}$. Tiene la agilidad y la destreza de los de 60. Le surge la curiosidad y me pregunta: "AArranco esta hierba?" "¿Esto qué es?" "CCómo se hace?" ¿Cómo se llama?" Puedes dejarle una picoleta, una azada o 
http://doi.org/10.15359/ree.25-1.9

http://www.una.ac.cr/educare

educare@una.ac.cr

un rastrillo, que son herramientas de cierto peligro, porque los utiliza correctamente. Tú no dirías que ahí hay un niño de 5 años. Porque Lucio, cuando está con el grupo de $6^{\circ}$, te sorprende.

Ha habido una variación importante en la manera en que Lucio vive la escuela y en cómo el resto vivimos la escuela con Lucio. Para que quiera estar aquí, para encontrarse con nosotros, hemos modificado la organización y hemos tenido que intervenir también en nuestra forma de observar, de reflexionar, de armar un proyecto común. Aunque a veces, por el motivo que sea, se rebota, te monta un jaleo, se cierra en sí mismo y ya no hay manera de entrar en relación con él. (CLAUDIA_FC_28)

Muchos de los testimonios procedentes de escuelas y colegios hablan, actualmente, de una gran dificultad para organizar la escena pedagógica. En la época de la sociedad disciplinaria, el proceso educativo estaba organizado como efecto de la validez y operatividad de los lugares prefijados (Deleuze, 2016). Bastaba con un sujeto docente y un sujeto estudiante que reprodujeran sus lugares atribuidos para que lo pedagógico se realizara; para lo cual, la norma institucional decretaba el inicio del fenómeno educativo. No obstante, en el momento en que las posiciones instituidas aparecen descompuestas y las bases institucionales de los centros educativos se fragmentan, la posibilidad o imposibilidad de la relación pedagógica no depende de la transmisión de conocimientos ni de la facilitación de aprendizajes, sino que depende de cómo responder a la crisis del encuentro con el otro sujeto.

El encuentro no se refiere un conjunto de individuos o a una reunión de figuras instituidas, el encuentro se refiere a los recursos y fuerzas con los que unos cuerpos cuentan para afectarse entre sí. No se sufre por el extravío de un rol investido, se sufre de aislamiento y de necesidad de relación, de carencia de personas interlocutoras con las que dar sentido a la existencia (Deleuze, 2002). El padecimiento está enlazado a la condición vulnerable de un cuerpo y, por tanto, a su capacidad de afectarse por y de afectar a las relaciones con los otros. La vulneración es la condición inicial para formular el encuentro como un verdadero problema: una formulación cuya fertilidad no reside en su adhesión a una legalidad externa a la situación, sino en su capacidad de intervenir en una práctica y de provocar que algo ocurra entre sus participantes.

Como consecuencia de la inestabilidad de las representaciones y del resquebrajamiento de los códigos reguladores, la vulnerabilidad es la condición que permite a los sujetos tomar conciencia del agotamiento de unos modos (Deleuze, 1996). Aquello que antes se reproducía ha perdido consistencia, las expectativas que se perseguían han dejado de conseguirse. La vulnerabilidad emerge como el punto de partida para pensar un encuentro con el otro ser, no el saber que concede poder y prefabrica el porvenir de las vidas, sino compartir la vulneración esencial que nos ubica en el territorio de la igualdad con el propósito de inventar nuevos movimientos. 
http://doi.org/10.15359/ree.25-1.9

Elcrecientedebilitamientodelosmecanismosinstitucionalesylarecurrentedesacreditación de los roles investidos conduce a una necesaria asunción de responsabilidad pedagógica -por la parte docente- para tomar decisiones en cuanto a cómo generar circunstancias que permitan acoger las diferentes y variadas formas de vida. Se puede ver en los fragmentos de conversación: las maestras se abren a un pensar activo que les lleva a experimentar nuevas composiciones a partir de aquello que se muestra -aparentemente- desmembrado (Deleuze, 2007). Se trata de un pensar que no trabaja identificando, clasificando y ordenando a los sujetos y a las prácticas según un modelo apriorístico, sino que se trata de un pensar que se esfuerza por interrumpir el curso natural de las cosas para inventar una organización que responda a la lógica de la significatividad singular y no de la reproducción de un patrón.

El desempeño de los roles estándares de estudiante y docente todavía arman el escenario educativo, no obstante, la fragilización de estas identidades trae cierta desaparición de las invariantes que aseguraban un sistema estable y, al mismo tiempo, esto fuerza a las educadoras y a los educadores a componer una trama común a partir de trabajos de afectación (Deleuze, 2016). Si los automatismos que estructuraban la relación educativa han dejado de ser operativos, la creación de una relación educativa debe pasar-necesariamente- por una alianza entre niñez y personal educativo construida a través de un hacer conjunto. Porque el desencuentro está garantizado cuando lo que se pone ahí es la expectativa de que el estudiantado satisfaga el modelo predefinido. Y porque docente no es solo aquella persona que sistematiza e implementa los compromisos que le han sido adjudicados por su papel institucional.

Crear las condiciones para el encuentro tiene que ver con imaginar intercambios e impulsar desplazamientos que tengan el poder de enlazar cuerpos, objetos y conceptos (Deleuze, 2007). Más allá de un activismo compulsivo que se esmera con urgencia por mejorar el rendimiento y por superarse en resultados, pero que no consigue hilar lazos entre las presencias, las condiciones para el encuentro remiten a la vulnerabilidad compartida, a la cercanía entre los cuerpos y a la igualdad de las potencias que nos ayuda a experimentar organizaciones inauditas.

\section{Conclusiones}

\section{Darse un cuerpo vulnerable (no erudito)}

Asumir que no se sabe es el punto de partida que permitió, a las maestras con las que se indagó, percibir sensiblemente cómo estaban Lucio y sus compañeros y compañeras, cuáles eran los deseos concernidos, cuáles las necesidades latentes, cómo entretejer una trama común, qué caminos abrían opciones y cuáles las cerraban. El encuentro con el niño no proponía resolver las particularidades de la vida de Lucio, sino suscitar lazos y afinidades (entre las maestras y el niño, entre este y sus pares, y entre el niño y la escuela) para ampliar las interpretaciones y los cuestionamientos, aumentar las potencias y multiplicar las posibilidades del porvenir. 
http://doi.org/10.15359/ree.25-1.9

http://www.una.ac.cr/educare

educare@una.ac.cr

En la época actual, marcada por la erosión de las figuras consolidadas que garantizaban la relación pedagógica, surge, como necesaria, una nueva manera de generar alianzas y colaboraciones entre los sujetos partícipes de la educación. Esta manera es la de la propia experiencia de la vulneración, que le permite al sujeto darse un cuerpo sensible al acogimiento y recepción de aquello que reconoce como incomprensible en el otro ser. La percepción de la indefensión y de la fragilidad en la otra persona activa la propia vulnerabilidad, de ahí que la posición vulnerable de quien educada se vuelva un recurso para propiciar el encuentro. Dicho de otro modo, cuando las maestras admiten su propia capacidad de ser afectadas por el otro sujeto y por la situación, dejan caer la rigidez de una actitud que pretendía defenderse de la diferencia de Lucio y se tornan susceptibles a los efectos impredecibles de la acogida del niño y a ponerse a pensar cómo hacer para encontrarse con él.

\section{Desorganizarse, moverse con lo moviente}

Un cuerpo no es una identidad invariable, un cuerpo es lo que su existencia es capaz de provocar. El lazo social entre cuerpos no es efecto de reproducir los cometidos institucionalizados, el lazo es consecuencia de la capacidad de afectar y de recibir afectación por una existencia singular. La hospitalidad de la acogida no examina "casos" desde una razón psicológica o médica ni decreta el futuro de los sujetos desde una perspectiva jurídica o administrativa, no consiste en proceder a la división de las vidas en lugares y posibilidades distintas. Los gestos de la acogida responden a la interpelación de la otra persona para generar una relación de confianza que facilite el encuentro; gestos que se verifican en situaciones en las que se buscan intercambios que permitan crecer en oportunidades para la conversación.

Una trama común no se entreteje tomando al otro para encauzarlo a un proyecto preexistente o a un entorno específico; lo común se configura haciéndonos sensibles a los múltiples y continuos afectos que los cuerpos implicados se causan entre sí. Las condiciones que favorecen el encuentro con Lucio no están puestas a priori, se articulan en el momento en que las maestras comienzan a cooperar con el niño: deben ser puestas -constituidas- en cada ocasión y se desvanecen cuando los cuerpos se distancian.

\section{Pensar fugando hacia otra distribución}

Esta investigación ha considerado el gesto de fugar como un modo de destapar otros territorios más habitables, más plurales, más comunes. Fugar se ha comprendido como una práctica que busca huir de las prescripciones estandarizadas para lograr atravesar las limitaciones de una estructura. Huir puede interpretarse como la potencia que un cuerpo tiene para perdurar en su existencia y eludir las coyunturas que disminuyen su fuerza. Fugar expresa el poder que un cuerpo tiene para transformarse en otro modo de ser al relacionarse con otros cuerpos, objetos y entornos que sí aumentan su fuerza. 
http://doi.org/10.15359/ree.25-1.9

Las maestras junto a quienes se ha investigado se preguntan sobre cómo hacer que la escuela se fugue con Lucio cuando este se fuga, con la idea de incrementar su hospitalidad y disponibilidad a la hora de inventar encuentros y actuaciones pedagógicas. De esta manera, la huida del niño descubre nuevos territorios donde puede componerse y realizar intercambios que le permitan expandir su vitalidad. En lugar de recolocar a Lucio en la posición que el centro educativo le dictamina, las maestras piensan problemáticamente el encuentro, esto es: aceptan la desorganización que el niño provoca en lo escolar y lo registran como un impulso para diferenciarse de lo programado y para repensarse como educadoras.

\section{Generar alianzas desde la sensibilidad}

Generalmente, un niño como Lucio es considerado como una obstrucción (una interferencia, una molestia) cuando se diferencia o desborda los rígidos mecanismos de un modelo institucional. Sin embargo, para el pensamiento esta situación es material sensible con el que iniciar un trabajo de creación de circunstancias que habiliten el encuentro educativo con dicho niño. Porque Lucio se expresa desarticulando del orden previsto y causando inquietud en la estructura, la diferencia que conlleva el niño permite abrir un campo posible de intercambios, experimentaciones, actividades y otras organizaciones.

Este trabajo demanda de las maestras y maestros estar subjetivamente implicados en el acontecimiento: ahí donde lo que sucede puede afectarles, y donde pueden intentar pruebas y ensayos inusuales; ahí donde pueden imaginar fugas e inaugurar nuevos movimientos. No se trata de una planificación que ejerce un control sobre el otro ser y lo subyuga a una serie de objetivos anteriores; sino de estar preparadas y preparados para componerse con las contingencias azarosas del día a día en la escuela; se trata de estar en disposición de armar un encuentro con las situaciones y los cuerpos que aparecen de improviso. Una disponibilidad que consiste en aprender a percibir el desplazamiento de las cosas y de los cuerpos para captar qué señales pueden resultar invitantes para orquestar un encuentro. Esta es una percepción que permanece mirando y escuchando los movimientos de los elementos que transitan la escuela, procurando leer qué puede o podría ocurrir organizando unas circunstancias y unos materiales $u$ otros.

\section{Declaración de Material complementario}

Este artículo tiene disponible, como material complementario:

-La versión preprint del artículo en https://doi.org/10.5281/zenodo.3661140 
http://doi.org/10.15359/ree.25-1.9

http://www.una.ac.cr/educare

educare@una.ac.cr

\section{Referencias}

Adorno, T. W. (2003). Notas sobre literatura. Akal.

Arbiol González, C. (2018). Elementos para una pedagogía de la alteridad en la práctica de educadoras sociales. Teoría de la educación, 30(2), 109-129. https://doi.org/10.14201/ teoredu02109129

Ávalos Latorre, M. L., Palos Toscano, M. Ú. y Miranda Álvarez, R. B. (Coords.) (2019). Prácticas y reflexiones sobre la educación contemporánea. Nómada. https://doi.org/10.47377/ GSJF3219

Ayala Carabajo, R. (2018). La relación pedagógica: En las fuentes de la experiencia educativa con van Manen. Revista Complutense de Educación, 29(1), 27-41. https://doi.org/10.5209/ $\underline{\text { RCED.51925 }}$

Bárcena, F. y Mèlich, J.-C. (2014). La educación como acontecimiento ético. Natalidad, narración y hospitalidad. Miño y Dávila.

Bergson, H. (2016). Memoria y vida. Alianza.

Biesta, G. J. J. (2017). El bello riesgo de educar. Cada acto educativo es singular y abierto a lo imprevisto. Ediciones SM.

Brailovsky, D. (2019). Pedagogía (entre paréntesis). Noveduc.

Clandinin, D. J., Caine, V., Lessard, S. y Huber, J. (2016). Engaging in narrative inquiries with children and youth. Routledge.

Clandinin, D. J., Caine, V. y Lessard, S. (2018). The relational ethics of narrative inquiry. Routledge.

Contreras Domingo, J. (Comp.) (2016). Tensiones fructíferas: Explorando el saber pedagógico en la formación del profesorado. Una mirada desde la experiencia. Octaedro.

Contreras Domingo, J. (Coord.) (2017). Enseñar tejiendo relaciones. Morata.

Contreras Domingo, J. y Pérez de Lara Ferré, N. (2010). La experiencia y la investigación educativa. En J. Contreras y N. Pérez de Lara Ferré (Comps.), Investigar la experiencia educativa (pp. 21 86). Morata.

Deleuze, G. (1987). Foucault. Paidós.

Deleuze, G. (1996). Conversaciones. Pre-textos.

Deleuze, G. (2002). Diferencia y repetición. Amorrortu.

Deleuze, G. (2006). Spinoza: Filosofía práctica. Tusquets. 
Deleuze, G. (2007). Dos regímenes de locos. Textos y entrevistas (1975-1995). Pre-textos.

Deleuze, G. (2016). Nietzsche y la filosofía. Anagrama.

Deleuze, G. y Guattari. F. (2010). Mil mesetas. Capitalismo y esquizofrenia. Pre-textos.

Deleuze, G. y Guattari, F. (2013). ¿Qué es la filosofía? Anagrama.

Deleuze, G. y Parnet, C. (1980). Diálogos. Pre-textos.

Dewey, J. (1998). Democracia y educación. Morata.

Gadamer, H-G. (1977). Verdad y método I. Sígueme.

Garcés, M. (2016). Fuera de clase. Textos de filosofía de guerrilla. Galaxia Gutenberg.

Kohan, W. (2019). Paulo Freire mais do que nunca: Uma biografia filosófica. Vestígio.

Larrosa, J. (2017). Pedagogía profana. Estudios sobre lenguaje, subjetividad, formación. Miño y Dávila.

Lévinas, E. (2015). Ética e infinito. Antonio Machado.

Meneses, J. (Coord.), Rodríguez-Gómez, D. y Valero, S. (2019). Investigación educativa: Una competencia profesional para la intervención. UOC.

Najmanovich, D. (2019). Complejidades del saber. Noveduc.

Sierra Nieto, J. E. (2019). Entre nuestras urgencias y sus deseos, la escucha. Márgenes, Revista de Educación de la Universidad de Málaga, 0(0), 119-122. http://dx.doi.org/10.24310/mgnmar. v0i0.6615

Sierra Nieto, J. E. y Blanco García, N. (2017). El aprendizaje de la escucha en la investigación educativa. Qualitative Research in Education, 6(3), 303-326. https://doi.org/10.17583/ gre.2017.2783

Skliar, C. (2017). Pedagogías de las diferencias (Notas, fragmentos, incertidumbres). Noveduc. van Manen, M. (2003). Investigación educativa y experiencia vivida. Idea Books. 